\title{
When national culture is disrupted: Cultural continuity and resistance to Muslim immigrants
}

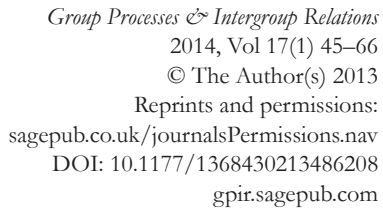

Group Processes \& Intergroup Relation. 2014, Vol 17(1) 45-66 (C) The Author(s) 2013 Reprints and permissions: sagepub.co.uk/journalsPermissions.nav DOI: $10.1177 / 1368430213486208$ gpir.sagepub.com

\section{Anouk Smeekes ${ }^{1}$ and Maykel Verkuyten ${ }^{1}$}

\begin{abstract}
In three studies we examined the importance of cultural continuity for attitudes towards Muslim immigrants. Study 1 showed that perceiving national culture to be temporally enduring predicted opposition to Muslim expressive rights, and this effect was mediated by perceptions of continuity threat. Studies 2 (survey) and 3 (experiment), examined whether attitudes towards Muslim immigrants are dependent on the specific content of cultural continuity. Study 2 showed that a stronger perception of religious tolerant continuity was associated with lower opposition to Muslims, via reduced levels of continuity threat, whereas a Christian continuity representation was associated with higher continuity threat and more opposition. In Study 3, the causal effect of religious tolerant continuity was the same, but the salience of Christian continuity only resulted in more opposition to Muslims among younger adults. Together, these findings illustrate the importance of perceptions and representations of cultural continuity for the understanding of current intergroup dynamics.
\end{abstract}

\section{Keywords}

continuity threat, cultural continuity, group history, opposition to Muslims

Paper received 10 April 2012; revised version accepted 13 March 2013.

Temporal continuity is an inherent feature of the human self. There is no sense of personal identity without a feeling that there is a link between past, present, and future (Epstude \& Peetz, 2012). When one's sense of self-continuity is disrupted this has various negative outcomes, for example in relation to mental health and well-being (e.g., Bluck \& Alea, 2008; Chandler \& Proulx, 2008). Next to the perception that one is temporally enduring as an individual, people are also inclined to see their groups - such as nations and ethnic communities_as being continuous over time (Sani, 2008; Sani et al., 2007). Collective continuity provides social identities with meaning, because it helps group members to understand where they come from and what constitutes their common and self-defining heritage (Liu \& Hilton, 2005; Sani et al., 2007). Although collective continuity has been a prominent topic of interest for

\footnotetext{
${ }^{1}$ Utrecht University, The Netherlands
}

\section{Corresponding author:}

Anouk Smeekes, Faculty of Social Sciences - ERCOMER, Utrecht University, Padualaan 14, PO Box 80.140, 3508 TC

Utrecht, The Netherlands.

Email: A.N.Smeekes@uu.nl 
historians, anthropologists, and sociologists (i.e., Hobsbawm \& Ranger, 1983; Lowenthal, 1985; Smith, 1998), research on the social psychological functions of collective continuity and its consequences for current group dynamics is more recent (Jetten \& Hutchison, 2011; Jetten \& Wohl, 2012; Sani, 2008; Sani, Bowe, \& Herrera, 2008a, 2008b; Sani et al., 2007; Smeekes, Verkuyten, \& Poppe, 2011, 2012).

It has been proposed that collective continuity can be understood in two different ways (Sani et al., 2008b; Sani et al., 2007): (a) "perceived cultural continuity" which refers to the preservation and continuation of some core, deeply ingrained, and unchanging cultural aspects, and (b) "perceived narrative continuity," which concerns the causally interconnectedness of historical phases and events that are represented in a coherent narrative. We propose that mainly cultural continuity is important for current group dynamics. The reason is that it is primarily the essentialist cultural understanding of in-group history that provides people with meaning to their collective identity and that stimulates strong group boundaries (Haslam, Bastian, Bain, \& Kashima, 2006; Liu \& Hilton, 2005). In addition, we argue that it is not only important to examine these different forms of collective continuity, but also the particular content of group identity that people see as temporally enduring. The content of group identity has normative properties that can have positive or negative consequences for intergroup relations, depending on what is seen as "our" traditional culture.

To show that cultural continuity rather than narrative continuity is important for understanding current intergroup relations, we investigated responses towards Muslim immigrants among Dutch natives. Muslim immigrants are often portrayed and perceived as a threat to the continuation of national culture and identity in Western Europe (Caldwell, 2009; Sniderman \& Hagendoorn, 2007). Circumstances or changes that are perceived as being incompatible with "who we have always been" disrupt a sense of cultural continuity. Rights of Muslims to publicly express their religiousness may be rejected because these expressions are perceived as threatening the continuation of the traditional culture, making it no longer the "same" national community. However, it is also possible to present the inclusion and acceptance of Muslim immigrants as a continuation of "our" historical culture of religious tolerance. A tradition of religious tolerance implies that allowing Muslims to publicly express their religion is not a threat to cultural continuity, but rather a confirmation of our traditional culture.

We present three studies to demonstrate the importance of cultural continuity for current intergroup dynamics. The first idea we wish to test is whether the two proposed dimensions of collective continuity are related to attitudes towards Muslim immigrants. We expected that only cultural continuity, and not narrative continuity, predicts these attitudes. Second, we aim to demonstrate that natives who perceive high cultural continuity will be more opposed to developments and groups that cause a rupture with the cultural past. More specifically, people who perceive high cultural continuity are expected to be more concerned about the preservation of their national culture and identity, and therefore to perceive more continuity threats from Muslim immigrants. These higher perceptions of continuity threat are subsequently expected to result in more opposition to expressive rights for Muslims. Finally, we aim to show that this sense of continuity threat is contingent on the specific content of cultural continuity. Following self-categorization theory (SCT; Turner, Hogg, Oakes, Reicher, \& Wetherell, 1987), we expected that natives who endorse a representation of Christian continuity are more likely to perceive Muslims as a continuity threat, and will consequently be more opposed to Muslim rights. In contrast, people who endorse a representation of religious tolerant continuity are expected to perceive less continuity threat, and consequently to display lower levels of opposition to Muslim rights.

\section{Perceived Collective Continuity}

Collective history is central in developing and shaping national identity. History provides people with an understanding of where they are coming 
from and what the foundations and contents of their national identity are (Liu \& Hilton, 2005). Since collective history gives people a sense of identity and grounding, individuals find comfort in the belief that their national group has temporal endurance. A growing body of research has shown that a sense of collective continuity provides existential security (Sani et al., 2008b; Sani et al., 2007; Sani, Herrera, \& Bowe, 2009). The reason is that even though individuals are aware that they themselves will ultimately die, collective continuity implies that the part of the self that is defined by group membership has transgenerational, temporal endurance-an eternal us (Jetten \& Hutchison, 2011; Reicher, 2008).

Following work on personal continuity by Chandler and Proulx (2008), Sani and colleagues (Sani et al., 2008b; Sani et al., 2007) have proposed that people's sense of collective continuity is grounded on two perceptions. "Perceived cultural continuity" (PCC) concerns the historical understanding of groups as possessing some core cultural elements that are not eroded by the passage of time, but transmitted from generation to generation. "Perceived narrative continuity" (PNC), refers to an understanding of history in which different historical periods and events are causally linked to another, and thereby form a coherent narrative. Sani and colleagues (Sani et al., 2008b; Sani et al., 2007) have developed a twodimensional scale to measure these perceptions of collective continuity, which was found to be internally consistent and valid across various European countries.

Although it has been shown that perceived collective continuity has a two-dimensional structure, previous research has not disentangled the cultural and narrative dimension in predicting intergroup relations. We propose that mainly cultural continuity is important for understanding current group dynamics. National group members feel particularly tied by the notion that they have shared beliefs, values, customs, and traditions that have endured throughout time and are passed on from generation to generation (Smith, 1998). For example, Condor (1997) found that Anglo-Britons' representations of "our national history" did not allude to chronological stories or historical events, but rather took the form of reified accounts often achieved with a reference to tradition. Furthermore, anthropologists speak about "participant primordialism" (Hutchinson \& Smith, 1996) and "everyday primordialism" (Gil-White, 1999) to indicate that laypeople tend to understand their ethnic and national group in terms of immutable and fixed cultural characteristics. This tendency is also referred to as "essentialism" in psychology.

According to Haslam (1998), one of the components of essentialism is the understanding of social categories as historically stable and enduring. Perceived cultural continuity contains this specific component of essentialism. In contrast, notions of essentialism are absent in the narrative understanding of group history (Chandler \& Proulx, 2008), as there are no references to the group's essential and unchanging traits. Social psychologists have shown that essentialist in-groups more strongly satisfy basic psychological needs related to group membership, than groups that are more mutable (e.g., Yzerbyt, Castano, Leyens, \& Paladino, 2000). Moreover, group boundaries tend to be relatively strong and exclusive for essentialized groups (see Haslam et al., 2006), and essentialist in-group perception is a precondition of infrahumanization of out-groups (Leyens et al., 2003). Therefore, perceived cultural continuity is likely to be related to exclusionary attitudes towards out-groups, whereas this is less probable for a narrative understanding of group history.

\section{When Cultural Continuity Is Threatened}

A sense of cultural continuity not only involves the past, but also the belief that "we" will continue to be in the future (Wohl, Branscombe, \& Reysen, 2010). A rupture in cultural continuity can be considered as a symbolic identity threat whereby group members are afraid that their cultural values and traditions will perish (Riek, Mania, \& Gaertner, 2006). However, whether group members will be concerned about continuity threat is likely to depend on the degree to which 
they perceive their in-group to be culturally continuous (Condor, 1997). Especially those who tend to perceive their in-group as culturally invariant and enduring should feel threatened by the increasing presence of cultural and religious newcomers. This is because these social changes undermine the feeling of in-group stability and continuity that provides group members with a sense of grounding and existential security. Specifically, the increasing presence and influence of cultural and religious out-groups represents a threat for people who perceive strong cultural continuity, because these developments may change the nature and identity of the in-group, and hence, may subvert its very essence.

When group members fear a rupture in the continuity of their identity they are likely to resist social changes in order to maintain and protect the cultural continuation of their in-group (Haslam, 1998). Recent studies have demonstrated that perceptions of collective continuity threat are associated with resistance to mergers (Jetten \& Hutchison, 2011) and opposition to immigration (Jetten \& Wohl, 2012). These findings illustrate that when people experience a threat to the continuity of their in-group identity they are prone to become negative towards developments and groups that are considered to be the source of this threat.

In the present research, we examined cultural continuity in the context of debates about the presence and visibility of Muslim immigrants in Western Europe. The increasing number of Islamic schools, Mosques, veiled women, and other visible signs of Islam are often represented as a threat to the traditional Western way of life, and as eroding "the authenticity of the nation from within" (Triandafyllidou, 1998, p. 602). Natives who perceive high cultural continuity should be especially opposed against expressive rights for Muslims, because they are prone to feel that Muslims represent a threat to the continuation of their national identity and culture.

\section{Content of Group Continuity}

The two dimensions of perceived collective continuity, as developed by Sani et al. (2007), refer to the specific form in which the collective past is understood. However, this does not tell us anything about the particular content of group identity that people perceive to be temporally enduring. According to self-categorization theory (Turner et al., 1987), group behavior is dependent on the beliefs, values, and norms that define the ingroup. SCT proposes that when group distinctions are salient, the norms and beliefs that define the in-group become part of the psychological self and consequently provide the guidelines for intergroup behavior. For example, it has been shown that the evaluation of immigrants depends on whether national identity is understood in ethnic or civic terms (e.g., Pehrson, Vignoles, \& Brown, 2009).

The content of national identity is typically defined in terms of the temporal endurance of core cultural characteristics (Condor, 1997; Verkuyten, 2003). However, this cultural content is not self-evident and can be defined in different ways with different normative implications. That is, different definitions of national culture are represented as invariant over time, in order to give authority to ideas about what the nation is like and hence how nationals should act (Reicher, 2008). Hence, in line with SCT, it can be predicted that whether people will experience continuity threats from immigrants is dependent on the particular content of national culture that is seen as continuous over time.

Within Europe, specific historical representations of national identity are invoked in order to argue whether the increasing presence and visibility of Muslims constitutes a threat to the continuation of national culture and identity. For example, some politicians and scholars have described European identity as being deeply rooted in the Christian tradition in relation to which Muslim immigrants constitute a visible “other" (Foner \& Alba, 2008; Zolberg \& Woon, 1999) and Islam a "bright boundary" (Alba, 2005, p. 33). Likewise, in the United States, the Christian roots and nature of American identity would make Muslims an "indigestible minority" (Huntington, 2004, p. 188). In such contexts, the perception and endorsement of Christian continuity may stand in the way of accepting Muslim 
immigrants, as they are seen as a threat to the continuation of "our" Christian cultural heritage (Smeekes et al., 2011). However, in various European countries, and the Netherlands in particular, there is also a strong emphasis on humanist values and a long tradition of religious tolerance (e.g., Smeekes et al., 2012). An emphasis on the tradition of religious tolerance implies that expressions of Islam do not threaten the continuation of national culture. Rather, allowing these expressions is in line with "our" tradition of religious tolerance and hence forms a continuation of "who we have always been."

\section{Overview of the Present Research}

In three studies, we examined how understandings of cultural continuity affect Dutch natives' attitudes towards Muslim immigrants. We firstly investigated the expectation that perceived cultural continuity (PCC) rather than perceived narrative continuity (PNC) predicts opposition to rights for Muslims to publicly express and confirm their religious identity (Study 1). Additionally, we tested the hypothesis that perceived cultural continuity hampers the acceptance of expressive rights for Muslims, because it makes people more likely to see Muslims as a threat to the continuation of the national culture.

In Study 2, and following SCT, we investigated how different contents of cultural continuity are related to opposition to Muslim expressive rights. We examined a Christian and a religious tolerant representation of cultural continuity, and predicted that a stronger endorsement of Christian continuity is associated with more resistance to Muslim rights, via higher levels of continuity threat. Contrastingly, stronger endorsement of religious tolerant continuity was expected to be associated with less opposition to Muslim rights, via lower perceptions of continuity threat. Study 3 tested the same predictions with an experimental design, among a representative sample of the native Dutch adult population.

In our studies, we examined the unique predictive power of different continuity representations, by controlling for relevant demographic characteristics. Previous research within the European context has shown that older and lower educated individuals, as well as males and Christians, tend to display more prejudice towards Muslim immigrants than younger, higher educated, female, and nonreligious individuals (see Helbig, 2012). Age and being Christian are furthermore relevant covariates, as they may affect perceptions of (Christian) cultural continuity. We therefore took age, gender, being Christian, and educational level (only in Study 3), into account in our analyses.

\section{Study 1}

The aim of this study was twofold. First, we examined whether the two dimensions of collective continuity (PCC and PNC) uniquely predict opposition to rights for Muslims to publicly confirm and express their identity. We expected that only PCC is related to opposition to Muslim rights. Second, we examined whether the predicted relationship between PCC and opposition to Muslim rights is mediated by the feeling that Muslims constitute a continuity threat.

\section{Method}

Participants and procedure. This study was conducted among 160 Utrecht University students. They participated on a voluntary basis and the questionnaires were completed within a classroom setting. We assessed whether participants were native Dutch by firstly asking them to indicate whether they had a Dutch passport (yes/no). Subsequently, the participants were asked to report whether they were religious (yes/no), and if so, which religion they felt affiliated to (open question). We only selected the participants who had a Dutch passport and did not adhere to one of the immigrant religions (e.g., Islam, Hinduism). ${ }^{1}$ This resulted in a total sample of 145 participants. This sample consisted of $24.4 \%$ men and $75.6 \%$ women. The ages ranged between 19 and $33(M=21.84, S D=2.65)$. The sample was relatively nonreligious $(78.4 \%)$, and those who indicated to be religious (21.6\%) were all Christian. 
Table 1. Item content and factor loadings for the cultural and narrative dimension of collective continuity, Study 1.

Factor 1 Factor 2

Cultural continuity

Dutch people have passed on their traditions across different generations

Shared values, beliefs and attitudes of Dutch people have endurance across time $\quad .77$

$\begin{array}{ll}\text { Throughout history the members of the Dutch group have maintained their } & .77\end{array}$

inclinations and mentality

Throughout history the Netherlands has maintained its own customs and

.73

traditions

Dutch people have maintained their values over time

.87

Narrative continuity

Dutch history is a sequence of interconnected events

Major phases in Dutch history are linked to one another

.58

.49

Netherlands $(r)$

There is a causal link between different events in Dutch history

.74

The main events in Dutch history are part of an "unbroken stream"

Note. Loadings $<.40$ are not shown, $(r)$, item is reverse-scored.

Measures. All responses were recorded on 7-point rating scales ranging from 1 (strongly disagree) to 7 (strongly agree), unless indicated otherwise.

Collective continuity. We used a 10-item scale from Sani et al. (2007) to assess perceptions of cultural and narrative continuity (PCC, PNC). Both subscales consist of five items (see Table 1). We performed a confirmatory factor analyses (CFA) using AMOS 16.0 software (Amos Development Corporation, 2007) to determine whether the items assessing PCC and PNC composed different factors. The proposed two-factor structure had an acceptable fit to the data, $\chi^{2}(33)=60.74, p=.002$; $\mathrm{CFI}=.95$, RMSEA $=.08$. However, the factor loadings showed that both the first items of the cultural and the narrative subscale had a factor loading below .40 (see Table 1). Removing these items resulted in a good model fit, $\chi^{2}(17)=27.14$, $p=.056$; CFI $=.98$, RMSEA $=.06$. We compared this model to a one-factor model in which the eight items were combined. Chi-square difference tests indicated that the two-factor model fit the data better than a one-factor model, $\chi^{2}(18)=$ 76.46, $p<.001, \Delta \chi^{2}(1)=52.32, p<.001$. Hence, we computed a PCC scale $(\alpha=.86)$ and a PNC scale $(\alpha=.75)$, each based on four items.
Continuity threat. We used three items $(\alpha=.83)$ to measure the extent to which participants perceived Muslims as a threat to the continuity of national culture: "Muslims in the Netherlands undermine the traditional Dutch way of life," "The maintenance of Dutch norms and values is threatened by the presence of Muslims," and "The Muslim way of life threatens the continuity of Dutch identity."

Opposition to Muslim expressive rights. We used a six-item scale ( $\alpha=.75)$ to assess participants' acceptance of the rights and opportunities for Muslims to publicly express and confirm their identity. These items have been used in previous Dutch studies (e.g., Smeekes et al., 2011; Verkuyten \& Yildiz, 2010) and two sample items are: "Muslims should have the right to not only celebrate their Islamic holidays at home, but also in public life," and "In the Netherlands wearing a headscarf should not be forbidden." Items were reverse-scored so that a higher score indicated more opposition to Muslim expressive rights.

Demographic characteristics. Gender (coded as $1=$ male, $0=$ female) and being Christian (coded as 1 
Table 2. Partial and nonpartial correlations for all measures, Study 1.

\begin{tabular}{lcllccc}
\hline & $M$ & $S D$ & 1 & 2 & 3 & 4 \\
\hline 1. Cultural continuity & 4.23 & 1.02 & - & $.49 * * *$ & $.22^{* *}$ & $.25^{* *}$ \\
2. Narrative continuity & 4.54 & 0.87 & $.53^{* * *}$ & - & .13 & .10 \\
3. Continuity threat & 2.80 & 1.26 & $.18^{*}$ & .14 & - & $.47^{* * *}$ \\
4. Opposition to Muslim rights & 3.04 & 0.96 & $.20^{*}$ & .13 & $.47^{* * *}$ & - \\
Covariates & & & & & & \\
6. Age & 21.84 & 2.65 & $-.31^{* *}$ & -.15 & -.07 & -.03 \\
7. Gender & - & - & $-.22^{* *}$ & -.10 & -.06 & .00 \\
8. Christian & - & - & .08 & .09 & .01 & .03 \\
\hline
\end{tabular}

Note. The correlations above the diagonal were calculated without controlling for the covariates. $* p<.05,{ }^{* *} p<.01,{ }^{* * *} p<.001$.

$=$ yes, $0=$ no) were assessed with two dummy variables. Age was a continuous measure in years.

\section{Results}

Preliminary analyses. Table 2 shows the descriptive findings for all variables, the bivariate correlations between the variables, as well as the partial correlations controlling for the demographic characteristics. Cultural continuity was positively correlated with continuity threat and opposition to Muslim rights. These correlations remained significant after controlling for the demographic characteristics. Narrative continuity was not significantly related to continuity threat and opposition to Muslim rights, and this did not change after including the demographics. This provides preliminary evidence that perceived cultural continuity is a unique predictor of negative attitudes towards Muslims and that it predicts these outcomes over and above demographic characteristics that have been demonstrated to be associated with prejudice towards Muslims. Moreover, these preliminary results indicated that age and gender were significantly correlated with PCC, but that being Christian was not related to any of the measured variables. We therefore collapsed for being Christian, and controlled for age and gender in the main analyses.

\section{Main Analyses}

Continuity threat. A stepwise regression analysis was performed to determine the effects of PCC and PNC on continuity threat. PCC and PNC were entered in Step 1, and age and gender were added in Step 2. As shown in Table 3, in Step 1, only PCC and not PNC significantly predicted continuity threat. The inclusion of age and gender in Step 2 did not significantly add to the explained variance in continuity threat, and Step 2 yielded similar results for the effects of PCC and PNC. Moreover, age and gender did not significantly predict continuity threat.

Opposition to Muslim rights. A similar procedure was used for the analysis of opposition to Muslim rights. Table 3 shows that only PCC and not PNC predicted opposition in Step 1, and that these results remained similar after age and gender were included in Step 2. Step 2 did not add to the explained variance in opposition, and both age and gender showed no significant relationship with measure.

Mediation analyses. As the previous analyses indicated, only PCC, and not PNC, significantly predicted continuity threat and opposition to Muslim rights. We therefore tested a mediation model where continuity threat would mediate the effect of PCC on opposition. We conducted another stepwise regression on opposition, where PCC was entered in Step 1, and continuity threat in Step 2. PCC significantly predicted opposition in Step $1, \beta=.25$, $t(137)=3.01, p=.002$, and although the coefficient of PCC remained significant in Step $2, \beta=.15$, $t(136)=2.11, p=.023$, it was reduced with $40 \%$. Importantly, continuity threat significantly predicted 
Table 3. Standardized $\beta$ values for the stepwise regressions of opposition to Muslim rights and continuity threat on cultural continuity, narrative continuity, and demographic characteristics, Study 1.

\begin{tabular}{llllll}
\hline & \multicolumn{2}{l}{ Continuity threat } & & \multicolumn{2}{c}{ Opposition to Muslim rights } \\
\cline { 2 - 3 } & Step 1 & & & Step 1 & Step 2 \\
\hline Cultural continuity & $.19 *$ & $.19 *$ & & $.21 *$ & $.23^{*}$ \\
Narrative continuity & .05 & .05 & & .03 & .02 \\
Age & & .02 & & & .06 \\
Gender & $.05 *$ & -.03 & & & $.03 *$ \\
$\mathrm{R}^{2}$ & & .05 & & .05 \\
$\mathrm{R}^{2}$ change & & .00 & & .00 \\
\hline
\end{tabular}

Note. $\sim p<.08,{ }^{*} p<.05, * * p<.01, * * * p<.001$.

opposition in Step 2, $\beta=.44, t(136)=5.81, p<.001$. Moreover, Step 2 accounted for a significant portion of variance in opposition to Muslim rights, $R^{2}$ $=.25, F(2,136)=22.50, p<.001 .^{2}$

We then used the Preacher and Hayes' (2008) bootstrapping macro for mediation, to test a model whereby continuity threat mediates the relationship between PCC and opposition to Muslim rights. In these analyses, mediation is significant if the $95 \%$ bias-corrected confidence intervals for the indirect (mediated) effect do not include zero. Results based on 1,000 bootstrapped samples indicated that zero was not included in the $95 \%$ confidence interval (lower CI $=.0198$, upper CI $=.1836) .{ }^{3}$ This provides evidence for mediation, whereby continuity threat mediates the positive relationship between cultural continuity and opposition to Muslim rights.

\section{Discussion}

Study 1 showed that perceived cultural continuity, and not narrative continuity, is important for understanding responses towards Muslim immigrants. A higher perception of cultural continuity was associated with more opposition to Muslim expressive rights and this relationship was mediated by perceived continuity threat. Thus, in line with our expectations, the more natives perceived their national culture as historically enduring, the more likely they were to perceive Muslim immigrants as causing a rupture with their cultural past, and subsequently the more they opposed expressive rights for this out-group.

People often perceive their culture as being historically stable, but they can have different understandings of which cultural values and traditions have endured. There are different representations of national history and culture and these can have implications for how people view immigrants and minority groups in the present (Sibley, Liu, Duckitt, \& Khan, 2008; Smeekes et al., 2011, 2012). We examined this possibility in a second study.

\section{Study 2}

In Dutch public debates about Islam different contents of national history and identity are evoked in order to argue for the inclusion or exclusion of Muslim immigrants. These different representations contain normative properties, as they serve to justify how "we" should deal with Muslims ("them"), based on the understanding of who "we" essentially were in the past, and hence, who "we" should be in the future (Liu \& László, 2007).

One important representation in the Dutch context is that of being a historically tolerant nation. Toleration of different worldviews and religions is often portrayed as a traditional, selfdefining aspect of Dutch national identity, and this historical representation is sometimes invoked to argue for the acceptance of Muslim immigrants (see Smeekes et al., 2012). At the same time there is also a representation that emphasizes the 
Christian roots of the Dutch culture and identity, and this is mostly used to argue for the exclusion of Muslim immigrants (see Smeekes et al., 2011). Although adherence to Christianity is weak in the Netherlands compared to other European countries, there exists a national discourse that presents Muslims as a threat to the continued importance of Christian values, norms, and practices.

In Study 2, we tested whether the endorsement of (a) religious tolerant continuity and (b) Christian continuity are differently related to opposition to Muslim expressive rights, via the perception of continuity threat. Following SCT, we predicted that stronger endorsement of religious tolerant continuity will be associated with lower opposition to Muslim rights, because this reduces perceptions of continuity threat. People who believe that their national in-group is historically characterized by religious tolerance should not feel threatened by Muslim immigrants, because the presence of this group represents a continuation of their national tolerant past. Contrastingly, natives who feel that Christian roots define the nation should be more likely to experience continuity threats from Muslims and therefore oppose them more strongly. This is because the increasing presence of religious others may subvert the Christian continuity of their national in-group.

\section{Method}

Participants. This study was conducted among 74 adolescents and young adults. Similar to Study 1, we only selected the participants who were Dutch (i.e., had a Dutch passport) and did not adhere to one of the immigrant religions (e.g., Islam, Hinduism). This resulted in a total sample of 70 native Dutch participants. They took part in the study on a voluntary basis and the questionnaires were completed within a classroom setting. The sample consisted of $41.4 \%$ men and $58.6 \%$ women. The ages ranged between 15 and 28 $(M=18.70, S D=4.10)$. Of all participants, $70 \%$ indicated to be nonreligious, and $30 \%$ said they were religious, and these were all Christian.
Moreover, the participants either followed a preuniversity track in high school $(62.9 \%)$ or already attended university (37.1\%).

Measures. The measures for continuity threat $(\alpha$ $=.82$ ), opposition to Muslim expressive rights $(\alpha=.79)$, and demographic characteristics (i.e., age, gender, and being Christian), were identical to Study 1.

Tolerant continuity (TC). We assessed the extent to which participants endorsed religious tolerant continuity with five items $(\alpha=.76$ ), based on measures that have been used in previous studies (see Smeekes et al., 2012). Since a sense of continuity not only involves the past but also the belief that we should continue to be in the future, we also included items in the scale that made reference to this future aspect. The items were: "Freedom of religion historically belongs to the Netherlands," "The Netherlands is traditionally an open and tolerant society where there is much room for other cultures and religions," "There has always been room for cultural and religious diversity in the Netherlands," "The Netherlands should remain a country where there is as much room for cultural diversity as possible," and "The Netherlands should remain a religiously tolerant country." The items were recorded on 7-point rating scales ranging from 1 (strongly disagree) to 7 (strongly agree).

Christian continuity (CC). The extent to which participants endorsed Christian continuity was measured with the following five items $(\alpha=.81)$ : "The Dutch have passed on their Christian traditions to next generations," "The Dutch identity is rooted in Christianity," "Christian norms and values have always been part of the Dutch identity," "The Netherlands should remain a country where Christian norms and values prevail," and "The Christian faith and its traditions should remain dominant in the Netherlands." All responses were recorded on 7-point rating scales ranging from 1 (strongly disagree) to 7 (strongly agree). 
Table 4. Partial and nonpartial correlations for all measures, Study 2.

\begin{tabular}{lllllll}
\hline & $M$ & $S D$ & 1 & 2 & 3 & \multicolumn{1}{l}{4} \\
\hline 1. Tolerant continuity (TC) & 4.91 & 1.01 & - & -.15 & $-.24^{*}$ & $-.52^{* * *}$ \\
2. Christian continuity (CC) & 3.87 & 1.17 & -.23 & - & $.33^{* *}$ & $.30^{*}$ \\
3. Continuity threat & 3.74 & 1.31 & $-.30^{*}$ & $.29^{*}$ & - & $.65^{* * *}$ \\
4. Opposition to Muslim rights & 3.81 & 1.09 & $-.55^{* * *}$ & $.29^{*}$ & $.65^{* * *}$ & - \\
Covariates & & & & & & .21 \\
5. Age & 18.70 & 4.10 & .12 & .20 & .20 & .20 \\
6. Gender & - & - & .06 & -.14 & -.09 & -.17 \\
7. Christian & - & - & .17 & $.34^{* *}$ & .18 & .02 \\
\hline
\end{tabular}

Note. The correlations above the diagonal were calculated without controlling for the covariates.

$* p<.05,{ }^{* *} p<.01, * * * p<.001$.

\section{Results}

Preliminary analyses. Table 4 shows the descriptive findings for all variables, the bivariate correlations between the variables, as well as the partial correlations controlling for the demographic characteristics. The correlation between tolerant continuity (TC) and Christian continuity (CC) was not significant indicating that these are separate constructs. Christian participants were more likely to endorse CC, and the endorsement of Christian continuity was positively correlated with continuity threat and opposition to Muslim rights. Contrastingly, TC was negatively correlated with continuity threat and opposition. These correlations remained significant after controlling for age, gender, and being Christian. This provides preliminary evidence that Christian continuity and tolerant continuity are unique (and opposite) predictors of continuity threat and opposition to Muslim rights, and predict these outcomes over and above relevant demographic characteristics. Moreover, these preliminary results showed that being Christian was significantly correlated with endorsing Christian continuity, but that age and gender were not related to any of the measured variables. We therefore collapsed across age and gender, and controlled for being Christian in the main analyses.

\section{Main analyses}

Continuity threat. A stepwise regression analysis was performed to determine the effects of TC and CC on continuity threat. TC and CC were entered in Step 1, and being Christian was added in Step 2. As shown in Table 5, in Step 1, both TC and $\mathrm{CC}$ predicted continuity threat. The inclusion of being Christian in Step 2 did not significantly add to the explained variance in continuity threat, and Step 2 yielded similar results for the effects of TC and CC. Moreover, being Christian did not exert a significant effect on continuity threat.

Opposition to Muslim rights. A similar procedure was used for the analysis of opposition to Muslim rights. Table 5 shows that both TC and CC predicted opposition in Step 1, and that these results remained similar in Step 2. Step 2 did not add to the explained variance in opposition, and being Christian was not related to this measure.

Mediation analyses. As the previous analyses indicated, both TC and CC significantly predicted continuity threat and opposition to Muslim rights. As a next step, we tested a mediation model in which continuity threat mediated the effects of TC and CC on opposition to Muslim rights (see Figure 1 for beta weights). When TC, $\mathrm{CC}$, and continuity threat were entered as predictors simultaneously, the regression equation accounted for a significant portion of variance in opposition to Muslim rights, $R^{2}=.56, F(3,66)$ $=28.46, p<.001$. Importantly, continuity threat significantly predicted opposition to Muslim rights. As shown in Figure 1, CC was no longer predictive of opposition when continuity threat 
Table 5. Standardized $\beta$ values for the stepwise regressions of opposition to Muslim rights and continuity threat on tolerant continuity, christian continuity, and control variables, Study 2.

\begin{tabular}{|c|c|c|c|c|}
\hline & \multicolumn{2}{|c|}{ Continuity threat } & \multicolumn{2}{|c|}{$\begin{array}{l}\text { Opposition to } \\
\text { Muslim rights }\end{array}$} \\
\hline & Step 1 & Step 2 & Step 1 & Step 2 \\
\hline Tolerant continuity (TC) & $-.20^{*}$ & $-.22 *$ & $-.49 * * *$ & $-.50^{* * *}$ \\
\hline Christian continuity (CC) & $.31^{* *}$ & $.26^{*}$ & $.22 *$ & $.21^{*}$ \\
\hline Christian & & .13 & & .04 \\
\hline$R^{2}$ & $.15^{* *}$ & $.16^{* *}$ & $.32 * * *$ & $.32 * * *$ \\
\hline$R^{2}$ change & & .01 & & .00 \\
\hline
\end{tabular}

Note. ${ }^{*} p<.05,{ }^{* *} p<.01,{ }^{* * *} p<.001$.

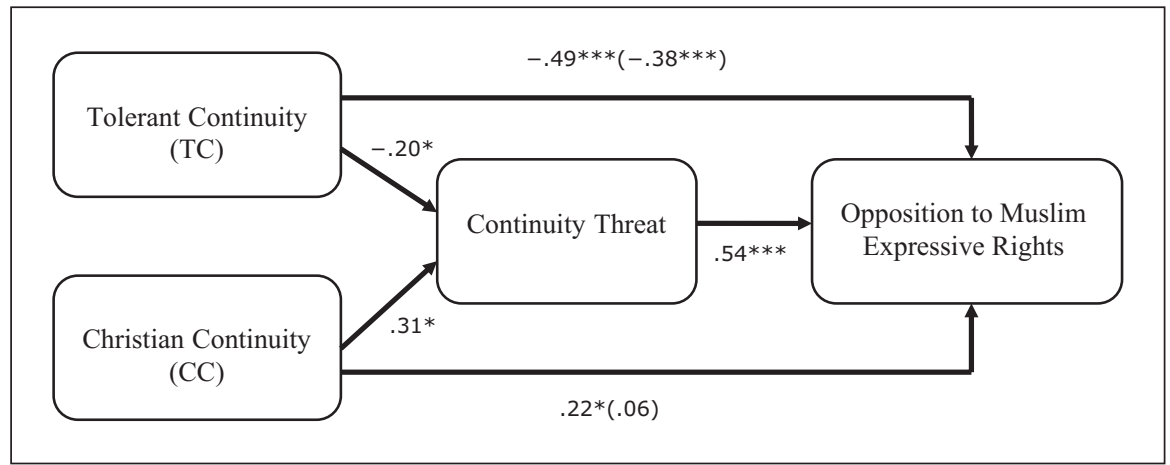

Figure 1. Mediation model with tolerant continuity and Christian continuity as the independent variables, continuity threat as the mediator, and opposition to Muslim expressive rights as the dependent variable, Study 2. Note. The direct effect coefficients shown in parentheses reflect the inclusion of the mediator in the equation. $*^{* *} *_{p}<.001,{ }^{*} p<.05$.

was entered into the equation. Although the coefficient of TC remained significant when continuity threat was entered into the equation it was reduced with $22.45 \%{ }^{4}$

We then tested whether continuity threat mediated the effect of TC and CC on opposition to Muslim rights using the Preacher and Hayes' (2008) bootstrapping macro for mediation. Results based on 1,000 bootstrapped samples indicated that zero was not included in the $95 \%$ confidence interval for both the indirect effect of TC (lower CI $=-.2660$, upper CI $=-.0300$ ) and of CC (lower CI $=.0757$, upper $\mathrm{CI}=.3197) .{ }^{5}$ This supports our prediction of mediation, whereby the effects of Christian and tolerant continuity on opposition to Muslim rights are mediated by continuity threat.

\section{Discussion}

In line with self-categorization theory, the results of Study 2 indicate that whether natives experience continuity threat and express opposition to Muslim rights depends on the particular content of cultural continuity that they endorse. The more people endorsed religious tolerant continuity, the less likely they were to oppose Muslim rights, whereas this effect was reversed for people who endorsed Christian continuity. Importantly, both these effects were mediated by continuity threat. A stronger endorsement of Christian continuity was associated with greater perceptions of continuity threat from Muslims, which subsequently resulted in more resistance to Muslim rights. Contrastingly, stronger endorsement of 
tolerant continuity was related to less opposition, via lower perceptions of continuity threat.

Since Study 2 was based on survey data we cannot make any claims about the causal order of the predicted effects. We therefore conducted a third study in which we manipulated Christian continuity and religious tolerant continuity to investigate whether this affects perceptions of continuity threat, and consequently opposition to Muslim rights. Moreover, since the previous studies were conducted among samples that were relatively young and highly educated, Study 3 used a representative national sample of the native Dutch adult population. This allows us to examine the generalizability of the findings of the previous study.

\section{Study 3}

Study 3 tested the same predictions as in Study 2. In addition, since there are no previous studies that have examined perceptions of collective continuity among nationally representative samples, Study 3 was also designed to test whether the effects of the Christian and tolerant continuity manipulations on attitudes towards Muslims would be dependent on relevant demographic characteristics of the respondents.

Following sociological studies on generations (Mannheim, 1964), we reasoned that it would be particularly important to examine whether historical understandings of national identity affect attitudes towards immigrant out-groups differently depending on the historical period in which the respondents grew up. Social scientists have argued and shown that individuals within a birth cohort experience similar societal circumstances during their formative years (Mannheim, 1964). They may be marked by these circumstances in such a way that the attitudes acquired in this crucial phase remain relatively stable throughout the rest of their lives. This notion has been adopted, among others, by Inglehart (1990) in his work on the diffusion of postmaterialism and a similar argument has been put forward by Sears (1993) in his symbolic politics theory. Additionally, research in the Netherlands has shown that cohorts that grew to maturity in times of large immigration waves or high unemployment rates display more widespread support for ethnic discrimination (Coenders, Lubbers, Scheepers, \& Verkuyten, 2008). We therefore examined different age cohorts in Study 3. Moreover, we also investigated interactive effects of the cultural continuity manipulations and other demographic characteristics (i.e., gender, being Christian, and education) that have been shown to be associated with attitudes towards Muslims.

\section{Method}

Participants. This study was conducted among a representative sample $(N=469)$ of the native Dutch population of 18 years and older. Participants received the questionnaire by means of an e-mail sent by TNS NIPO Consult. ${ }^{6}$ Respondents were drawn from a panel of respondents maintained by TNS NIPO Consult. On our request, this company only approached panel members who possess a Dutch passport and whose parents are both born in the Netherlands. The characteristics of this sample closely match those of the native Dutch population. The sample consisted of $52.2 \%$ men and $47.8 \%$ women. The ages ranged between 18 and 88 , and the mean age was $50.28(S D=16.98)$. Of the respondents, $4.3 \%$ completed primary education, $58.9 \%$ completed a lower level of secondary (26.7\%) and tertiary education (32.2\%), 36.2\% completed a higher level of secondary $(8.7 \%)$ and tertiary (higher applied and university) education $(27.5 \%)$, and $0.6 \%$ did not report their educational level.

Procedure. A between-subjects design was used, in which participants were randomly assigned to one of three conditions: Christian continuity, religious tolerant continuity, or a control condition. In the Christian and religious tolerant continuity conditions, participants first read a short introductory paragraph that was followed by a writing assignment. These manipulations were similar to those used in previous studies (see Smeekes et al., 2011, 2012). Participants in the control condition did not receive an introductory paragraph or writing task. In the Christian continuity condition participants read the following: 
Historians have convincingly shown that the Netherlands is originally a Christian country. Christian norms and values have been a central part of the Dutch identity since the Middle Ages. The Dutch have always been inspired by Christian traditions and Christian customs and traditions can still be found everywhere in present Dutch society. Christian inheritance is thus a historical key aspect of Dutch identity. Please describe in maximum 3 sentences why the maintenance of Christian customs and traditions is important for the continuity of Dutch culture and identity.

Participants in the religious tolerant continuity condition received the following text:

Historians have convincingly shown that in the Netherlands people from different religions have been living together for a very long time. Three hundred years ago the Dutch were already in favor of freedom of religion. In the 17 th century, foreigners were impressed by the liberties that Catholics, Jews, Lutherans, Mennonites, and controversial writers (like Spinoza) enjoyed here. This history of religious tolerance provides the roots of Dutch identity. Please describe in maximum 3 sentences why the maintenance of the tradition of religious tolerance is important for the continuity of Dutch culture and identity.

After the writing task participants completed a questionnaire that contained the measures for continuity threat, opposition to Muslim rights, and demographic variables.

Measures. The items assessing opposition to Muslim rights $(\alpha=.91)$ were similar to Studies 1 and 2. Continuity threat $(\alpha=.90)$ was measured with the same three items as used in the previous studies, plus one additional item: "Despite the growing number of Muslims, the Netherlands is able to maintain its original customs and traditions." This item was reverse-scored. We focused on the same demographic variables as in the previous studies, and also included educational level, which was measured by asking people to indicate their highest obtained educational degree, ranging from 1 (primary education) to 8 (university degree). We divided participants into four age cohorts $(18-35,35-50,50-65,65+)^{7}$ and created a dummy variable for each cohort. We constructed an additional variable to measure Christian religiosity by combining two measures: (a) being Christian or not (dummy-coded), and (b) religiosity (7-point scale). This new scale ranged from 1 (non-Christian and nonreligious) to 7 (Christian and highly religious). Gender was again measured with a dummy variable $(0=$ female, 1 $=$ male $)$.

\section{Results}

All variables were analyzed using multiple regression procedures, whereby two separate dummy variables were created for the cultural continuity manipulations (see Aiken \& West, 1991). The first dummy variable concerned the Christian continuity manipulation (coded as $1=$ Christian, $0=$ tolerant, $0=$ control), and the second dummy the religious tolerant continuity manipulation $($ coded as $1=$ tolerant, $0=$ Christian, $0=$ control).

Preliminary analyses. We first examined whether the responses to the cultural continuity manipulations differed by gender, age cohorts, Christian religiosity (centered), and educational level (centered). For each of these variables, interaction terms were created by multiplying them with the Christian and tolerant dummy variables (see Aiken \& West, 1991). Both continuity threat and opposition to Muslim rights were regressed on each of these demographic variables and the experimental dummy variables, and subsequently on their interaction terms. Because the main $\left(p_{\mathrm{s}}>\right.$ .33) and interaction effects of gender $\left(p_{\mathrm{s}}>.45\right)$ were not significant for any of the dependent variables, we collapsed across participant gender for all subsequent analyses. Christian religiosity had a significant main effect on opposition to Muslim rights, $\beta=-.14, p=.003$, but not on continuity threat, $\beta=-.01, p=.795$, and there 
Table 6. Standardized $\beta$ values for the regression of continuity threat and opposition to Muslim rights on the experimental manipulations, age cohort, and the Christian manipulation by age cohort interactions, Study 3 .

\begin{tabular}{|c|c|c|c|c|}
\hline & \multicolumn{2}{|c|}{ Continuity threat } & \multicolumn{2}{|c|}{$\begin{array}{l}\text { Opposition to } \\
\text { Muslim rights }\end{array}$} \\
\hline & $\beta$ & $p$ & $\beta$ & $p$ \\
\hline \multicolumn{5}{|l|}{ Experimental manipulation } \\
\hline Christian continuity & .24 & .023 & .28 & .008 \\
\hline Tolerant continuity & -.09 & .077 & -.12 & .022 \\
\hline \multicolumn{5}{|l|}{ Age cohorts $(18-35=$ ref $)$} \\
\hline $35-50$ & .09 & .202 & .10 & .150 \\
\hline $50-65$ & .13 & .062 & .06 & .376 \\
\hline $65+$ & .06 & .352 & -.06 & .373 \\
\hline \multicolumn{5}{|l|}{ Interaction effects (18-35 = ref) } \\
\hline $35-50 *$ Christian continuity & -.23 & .006 & -.25 & .002 \\
\hline $50-65 *$ Christian continuity & -.10 & .234 & -.16 & .067 \\
\hline $65+*$ Christian continuity & -.19 & .013 & -.15 & .053 \\
\hline
\end{tabular}

Note. Two-sided $p$-values are reported.

were no interaction effects with the continuity manipulations on any of the dependent measures $\left(p_{\mathrm{s}}>.23\right)$. Education had significant main effects on continuity threat, $\beta=-.25, p<.001$, and opposition to Muslim rights, $\beta=-.30, p<.001$, but showed no significant interactions with the experimental manipulations $\left(\phi_{\mathrm{s}}>.23\right)$.

Finally, we examined the effects of the separate age cohort dummies, as well as their interactions with the Christian and tolerant manipulations. None of the interactions between the tolerant manipulation and age cohorts were significant for any of the dependent measures $\left(\phi_{\mathrm{s}}\right.$ $>$.30). Although there were no main effects of the different age cohorts on any of the dependent measures, there were significant interactions between the Christian manipulation and the different age cohorts (see Table 6). These interactions revealed that the effect of the Christian manipulation tended to be somewhat stronger for the youngest age cohort compared to the older age cohorts. ${ }^{8}$ Moreover, looking at the effects of the Christian manipulation versus the control condition (on both dependent measures) within each age cohort revealed that there were only significant differences within the youngest age cohort and not within the older ones (see
Table 7 for means and standard deviations of continuity threat and opposition to Muslim rights by Christian vs. control condition within each age cohort).

These preliminary results indicate that educational level and Christian religiosity were related to attitudes towards Muslims, and that the effect of the Christian manipulation was only significant within the youngest age cohort. We therefore performed the main analysis in two steps. In Step 1 the two dummy variables for the Christian and tolerant manipulation were entered, and in Step 2 we added Christian religiosity, education, age cohort (dummy-coded as: 1 = youngest age cohort, 0 $=$ older age cohorts), and the interaction between age cohort and the Christian manipulation. ${ }^{9}$

\section{Main analyses}

Continuity threat. In Step $1, R^{2}=.01, F(2,466)$ $=2.33, p=.049$, there was a main effect of the religious tolerant manipulation, showing that participants in the tolerant condition reported less continuity threat than participants in the control condition, $\beta=-.09, t(466)=-1.70, p=.045$. The Christian manipulation had no significant effect on continuity threat, $\beta=.017, t(466)=0.33, p=$ .372. Step 2 significantly added to the explained 
Table 7. Mean levels of continuity threat and opposition to Muslim rights by Christian vs. control condition and age cohort, Study 3.

\begin{tabular}{|c|c|c|c|c|c|c|}
\hline & \multicolumn{3}{|c|}{ Christian continuity } & \multicolumn{3}{|c|}{ Control } \\
\hline & $M$ & $S D$ & $n$ & $M$ & $S D$ & $n$ \\
\hline \multicolumn{7}{|l|}{ Continuity threat } \\
\hline Age cohort (18-35) & $4.58_{\mathrm{a}}$ & 1.21 & 29 & $3.87_{b}$ & 1.41 & 43 \\
\hline Age cohort (35-50) & $3.69 \mathrm{a}$ & 1.46 & 41 & $4.32_{\mathrm{a}}$ & 1.37 & 34 \\
\hline Age cohort (50-65) & $4.51_{\mathrm{a}}$ & 1.61 & 51 & $4.13_{\mathrm{a}}$ & 1.50 & 54 \\
\hline Age cohort $(65+)$ & $3.68_{a}$ & 1.68 & 31 & $4.01_{\mathrm{a}}$ & 1.38 & 29 \\
\hline \multicolumn{7}{|c|}{ Opposition to Muslim rights } \\
\hline Age cohort (18-35) & $5.13 \mathrm{a}$ & 1.33 & 29 & $4.38_{b}$ & 1.32 & 43 \\
\hline Age cohort (35-50) & $4.20_{\mathrm{a}}$ & 1.45 & 41 & $4.77_{\mathrm{a}}$ & 1.31 & 34 \\
\hline Age cohort (50-65) & $4.61_{\mathrm{a}}$ & 1.54 & 51 & $4.43 \mathrm{a}$ & 1.45 & 54 \\
\hline Age cohort $(65+)$ & $4.099_{\mathrm{a}}$ & 1.46 & 31 & $3.91_{\mathrm{a}}$ & 1.24 & 29 \\
\hline
\end{tabular}

Note. Comparisons in each row with differing subscripts are significantly different at $p<.05$ (two-sided).

variance in continuity threat, $\Delta R^{2}=.07, \Delta F(4$, $462)=9.06, p<.001$. Education was significantly related to continuity threat, $\beta=-.24, t(462)=$ $-5.45, p<.001$, but Christian religiosity was not, $\beta=-.01, t(462)=-0.18, p=.859$. Moreover, Step 2 yielded similar results for the effects of the experimental manipulations. The effect of the tolerant manipulation remained significant, $\beta=$ $-.10, t(462)=-1.97, p=.025$, and the effect of the Christian manipulation remained nonsignificant, $\beta=-.04, t(462)=-0.67, p=.253$. There was no significant main effect of age cohort, $\beta=$ $-.07, t(462)=-1.32, p=.188$, but the Christian manipulation by age cohort interaction was significant, $\beta=.12, t(462)=2.15, p=.032$. Looking at the simple slopes revealed that the Christian manipulation had a significant positive effect for the youngest age cohort, $\beta=.22, t(99)=2.06, p$ $=.042$, but did not significantly change continuity threat for the older cohorts, $\beta=-.04, t(364)$ $=-.66, p=.509$.

Opposition to Muslim rights. The same procedure was used for examining opposition to Mus$\lim$ rights. In Step $1, R^{2}=.02, F(2,466)=4.65, p$ $=.005$, there was a main effect of the religious tolerant manipulation, showing that participants in the tolerant condition reported less opposition than participants in the control condition, $\beta=$ $-.12, t(466)=-2.31, p=.011$. The Christian manipulation had no significant effect on opposition, $\beta=.03, t(466)=0.61, p=.273$. Step 2 significantly added to the explained variance in opposition, $\Delta R^{2}=.12, \Delta F(4,462)=15.62, p<$ .001. Both education and Christian religiosity were negatively related to opposition, $\beta=-.29$, $t(462)=-6.64, p<.001, \beta=-.13, t(462)=$ $-2.93, p=.004$, respectively. Importantly, Step 2 yielded similar results for the effects of the experimental manipulations. The effect of the tolerant manipulation remained significant, $\beta=-.12$, $t(462)=-2.35, p=.010$, and the effect of the Christian manipulation remained nonsignificant, $\beta=-.02, t(462)=-0.37, p=.357$. There was no significant main effect of age cohort, $\beta=-.02$, $t(462)=-0.43, p=.667$, but the Christian manipulation by age cohort interaction was significant, $\beta=.13, t(462)=2.36, p=.019$. Looking at the simple slopes revealed that the Christian manipulation had a significant positive effect for the youngest age cohort, $\beta=.23, t(99)=2.24, p=$ .027 , but did not significantly change opposition for the older cohorts, $\beta=-.02, t(364)=-0.33$, $p=.739$.

Mediation analyses. The previous analyses showed that there was a significant effect of the tolerant manipulation, and of the Christian manipulation by age cohort interaction, on continuity threat and opposition to Muslim rights. As a next step, 
we added continuity threat to the equation that was conducted in Step 2 for opposition to Muslim rights (see analyses shown in the previous section), $R^{2}=.53, F(7,461)=74.37, p<.001$. Importantly, continuity threat significantly predicted opposition to Muslim rights, $\beta=.66, t(461)$ $=19.67, p<.001$. When continuity threat was entered into the equation, the effect of the tolerant manipulation, $\beta=-.05, t(461)=-1.37, p=$ .085 , and the Christian manipulation by age cohort interaction, $\beta=.05, t(461)=1.23, p=$ .110 , were no longer significant.

We then tested whether continuity threat mediated the main effect of the tolerant manipulation (coded as: $1=$ tolerant, $0=$ Christian, $0=$ controh), as well as the interactive effect of the Christian manipulation (coded as: $1=$ Christian, $0=$ tolerant, $0=$ control) and age cohort (coded as: $1=$ youngest age cohort, $0=$ older age cohorts), on opposition to Muslim rights (controlling for the unique effects of the Christian manipulation and age cohort). We tested this prediction with bootstrapping, using Preacher and Hayes' (2008) macro for mediation. Results based on 1,000 bootstrapped samples indicated that zero was not included in the $95 \%$ confidence interval for the indirect effect of the tolerant manipulation (lower CI $=-.3690$, upper CI $=-.0139)$. This provides evidence for mediation, where (reduced levels of) continuity threat mediated the negative effect of the tolerant manipulation on opposition to Muslim rights. Moreover, this analysis also revealed a significant positive indirect effect of Christian manipulation by age cohort interaction on opposition (lower CI $=.1187$, upper $\mathrm{CI}=1.0612) .{ }^{10}$ This provides evidence for mediated moderation, where continuity threat mediated the interactive effect of age cohort (youngest vs. older) and Christian continuity on opposition to Muslim rights.

\section{Discussion}

Consistent with the results of Study 2, Study 3 indicated that whether people experience continuity threat and express opposition to Muslim rights is dependent on the particular content of cultural continuity. When the continuity of the
Dutch tradition of religious tolerance was salient, participants displayed lower opposition to Muslim expressive rights, because they perceived less continuity threat. Furthermore, Christian continuity salience resulted in higher perceptions of continuity threat, and more opposition to Muslim rights, among the youngest age cohort (18-35), but not among the older ones. These findings provide an interesting addition to Study 2, because they illustrate that the effect of religious tolerant continuity on attitudes towards Muslims can be generalized across different age cohorts, whereas this is not the case for Christian continuity.

A possible explanation for this cohort effect is that the meaning ascribed to Christian cultural heritage, as well as its associations with the evaluation of ethnic and religious out-groups, such as Muslims, vary between the different generations. This interpretation is in line with sociological theories and findings on generations (Coenders et al., 2008; Inglehart, 1990; Mannheim, 1964), which propose that age cohorts have different attitudes, because of the different societal circumstances during their formative years. In the Netherlands, Christian religiosity was very strong until the beginning of the 1970s, but has sharply declined since the mid-1970s (Dekker, 2007). This means that people in the oldest age cohorts are likely to have (had) more personal experiences with Christianity (e.g., have often been raised in a Christian fashion) than the younger generations, and therefore may have a different interpretation of what constitutes Christian cultural heritage. For the older generations, thinking about Christian cultural heritage might activate prosocial norms of solidarity, care and love for fellow human beings, which are likely to have more positive implications for the acceptance of immigrant groups (Hunsberger \& Jackson, 2005). For the youngest generation, understandings of Christian continuity may be more strongly linked to the current political discourse on immigration, in which the continuation of "our" Christian cultural heritage is discussed in relation to the alleged continuity threats posed by Muslim immigrants (Foner \& Alba, 2008; Smeekes et al., 2011; Zolberg \& Woon, 1999). 


\section{General Discussion}

The main aim of our research was to demonstrate the importance of cultural continuity for current group processes and intergroup relations. We examined our expectations in the context of the increasing presence and visibility of Muslim immigrants in Western Europe and the negative sentiments of the native populations that accompany this development (Caldwell, 2009; Sniderman \& Hagendoorn, 2007). Across three studies, we demonstrated that perceptions and representations of cultural continuity are related to feelings of continuity threat and opposition to expressive rights for Muslims.

In social psychology, there have been few studies on how perceptions of collective continuity inform current intergroup processes (see Jetten \& Hutchison, 2011; Jetten \& Wohl, 2012), and to our knowledge, no previous studies have disentangled the roles of the two dimensions of collective continuity (Sani et al., 2008b; Sani et al., 2007). We predicted that cultural, rather than narrative, continuity would be associated with feelings of continuity threat and opposition to Muslim immigrants. This is because, in contrast to narrative continuity, perceived cultural continuity contains a component of essentialism that discounts the notion of cultural change and fluidity (Haslam, 1998), which hinders acceptance of the increasing presence of cultural and religious others. As expected, Study 1 showed that only higher perceived cultural continuity was associated with a stronger belief that Muslim immigrants constitute a threat to the continuation of national identity, and this, in turn, predicted stronger opposition to Muslim rights.

These different dimensions of perceived collective continuity concern the form in which people understand their collective past. Yet, this does not tell us anything about the particular content of group identity that people consider to be temporally enduring. According to SCT, the content of group identity guides intergroup attitudes and behavior (Turner et al., 1987), and we therefore expected that different contents of cultural continuity are important for attitudes towards out-groups. We focused on a Christian and religious tolerant representation of cultural continuity, and found that the endorsement of religious tolerant continuity was associated with lower opposition to Muslim rights via reduced perceptions of continuity threat. In contrast, stronger endorsement of Christian continuity was associated with higher perceived continuity threat and this resulted into stronger opposition to Muslim rights (Study 2). In Study 3, we experimentally manipulated the salience of Christian versus religious tolerant continuity among a representative sample of the native Dutch population, in order to examine the causality and generalizability of these findings. In line with Study 2, the salience of religious tolerant continuity decreased opposition of Muslim immigrants via lower feelings of continuity threat. In addition, Study 3 revealed that the salience of Christian continuity only increased opposition to Muslim rights, via enhanced continuity threat, among the youngest age cohort (18-35) and not among the older ones.

\section{Implications, Limitations, and Directions for Future Research}

The finding that perceptions and representations of the collective past are related to how natives evaluate immigrants in the present, underlines the importance of taking group history and a sense of continuity into account when examining current intergroup relations. Group members understand their shared identity in terms of their collective history and culture (Jetten \& Hutchison, 2011; Sani et al., 2008b; Sani et al., 2007; Sani et al., 2009), and this affects how they evaluate future developments, such as the presence of cultural and religious others (Jetten \& Wohl, 2012). Importantly, there can be different, often contested, representations of what constitutes "our shared cultural heritage" and this is important for whether group members evaluate social developments as forming a rupture or continuation of their identity. As such, these different representations of cultural continuity can be strategically used by politicians to mobilize the electorate in favor, or against, the presence of immigrant 
out-groups (Reicher, 2008; Sibley et al., 2008; Smeekes et al., 2011, 2012).

Haslam (1998) has argued that the perception of social categories as historically stable is a component of essentialism, but studies on cultural essentialism have tended to ignore this temporal aspect (e.g., Fischer, 2011). In addition, previous research has typically looked at the different ways in which out-groups (e.g., women, Black people, gay men, liberals) are essentialized and how this relates to prejudice towards these groups (e.g., Haslam, 1998; Haslam et al., 2006). Fewer studies have looked at the distinct ways in which the ingroup is essentialized and how this informs current intergroup relations (Leyens et al., 2003; Verkuyten, 2003). The concept of cultural continuity can be understood as the temporal dimension of in-group essentialism. It is likely that this dimension correlates with other components of essentialism (e.g., immutability, naturalness, entativity), and future studies should examine how these components of in-group essentialism are related to out-group evaluations. Additionally, while our research highlights the importance of perceptions of collective continuity in an intergroup context, studies have shown that these perceptions also have intragroup implications, for example by enhancing in-group identification (see Sani et al., 2008b; Sani et al., 2009). The extent to which group members perceive cultural continuity is likely to influence behaviors aimed at strengthening the in-group and protecting the national culture, even in the absence of a threatening out-group. These predictions could be examined in future work.

The few experimental studies that have been conducted in relation to in-group continuity and intergroup processes (e.g., Jetten \& Wohl, 2012) have only used relatively young and highly educated samples, and have not examined different contents of cultural continuity. Hence, an interesting and novel finding of the present research (Studies 2 and 3) is that the salience of Christian continuity triggered more negative attitudes towards Muslims among the youngest age cohort (18-35), but not among the older ones. This finding was not predicted and we therefore encourage future research to more closely examine the different meanings that people ascribe to Christian cultural heritage, how this relates to current group evaluations, and whether this differs across generations. More generally, these findings underline the importance for social psychological research to look at diverse age cohorts when examining perceptions of group history and current intergroup processes.

Another notable finding of Study 3 is that a higher level of Christian religiosity was associated with lower opposition towards Muslim expressive rights. This result may indicate that being religious makes people more likely to support the right to live according to one's religion, even if this concerns a religious out-group. The Netherlands is one of the most secular countries in Europe (with about $50 \%$ being nonreligious), and religious groups have a minority position. Although there have been recent tensions between different religious communities in the Netherlands, these communities have also defended the general right to practice one's religion and to establish religious schools. This means that Christians may display lower opposition to Muslim rights, because such religious minority rights also allow them to maintain their Christian way of life. Future studies should more closely examine the interplay between Christian religiosity, the endorsement of Christian continuity, and attitudes towards Muslim rights.

A further important result of the current research is that the endorsement and salience of religious tolerant continuity was associated with less negative attitudes towards Muslim immigrants (Studies 2 and 3). One implication of this finding is that a representation of a continuing cultural tradition of religious tolerance can make natives more accepting towards Muslim immigrants. However, it must be noted that this national tradition of tolerance can also be used to argue for, and justify, discrimination of immigrant outgroups (Verkuyten, 2013). Muslim immigrants are sometimes portrayed as being intolerant themselves and therefore as a threat to "our" national tradition of tolerance. We focused on a more inclusive representation of religious tolerance, but 
it is important for future work to study both inclusive and exclusive uses and consequences of representations of tolerant continuity.

The present research demonstrated the importance of cultural continuity in the context of relatively strong negative sentiments towards Muslim immigrants in the Netherlands (Sniderman \& Hagendoorn, 2007). It is likely that these findings are not limited to this setting but apply to other countries and to other social developments that are considered a threat to the continuity of a collective identity, such as increasing European integration or mergers between organizations. Yet, there may be limits in the extent to which these findings can be generalized to countries or groups with a relatively young history (e.g., Australia), in which perceptions of cultural continuity may be less important in defining national identity. Likewise, other findings could be observed among groups and countries with a strong negative history, such as Germany. In these countries natives might be inclined to emphasize cultural discontinuity in order to distance themselves from the past and to maintain a positive sense of national group membership (Bilewicz, 2007; Sahdra \& Ross, 2007).

\section{Conclusions}

In three studies, we demonstrated that perceptions and representations of cultural continuity are important for current attitudes towards Muslim immigrants. Importantly, and in line with SCT, we showed that whether people perceive continuity threat, and consequently oppose expressive rights for Muslim immigrants, depends on the specific contents of national culture that are seen as temporally enduring. These findings are relevant, as they go beyond the familiar social psychological explanations of out-group attitudes and attitudes towards immigrants in particular (Brown, 2010; Wagner, Christ, \& Heitmeyer, 2010). In studying intergroup relations, social psychologists tend to focus on the synchronic dimension of social life, and are much less concerned with the diachronic (i.e., temporal) dimension. However, current intergroup perceptions, feelings, and behaviors are often influenced by thoughts of past times and by feelings of in-group continuity (Condor, 1996; Epstude \& Peetz, 2012; Jetten \& Wohl, 2012). By showing that temporal understandings of national culture and identity guide attitudes towards immigrants this research more generally illustrates that perceptions of group history are important for understanding current group dynamics.

\section{Notes}

1. We only had a measure of Dutch nationality and not of ethnic origin. Hence, it is possible that some participants in the sample had a nonnative background. However, Utrecht University has a very low percentage of Dutch students with such a background $(8 \%)$. Moreover, with the question on religious affiliation we could filter out the participants who adhered to an immigrant religion (e.g., Islam, Hinduism). Therefore, the amount of nonnative Dutch participants in this sample is negligible.

2 . We repeated the analysis including age and gender and this yielded similar results for PCC $(\beta=.14, p$ $=.045)$ and continuity threat $(\beta=.47, p<.001)$. Age and gender were not significantly related to opposition in this analysis $\left(\phi_{\mathrm{s}}>.57\right)$.

3. When repeating this analysis including age and gender this yielded similar results (lower CI = .0185 , upper $\mathrm{CI}=.1900$ ).

4. We repeated the analysis including the dummy variable for being Christian and this yielded similar results for TC $(\beta=-.37, p<.001), \mathrm{CC}(\beta=.07, p$ $=.458)$, and continuity threat $(\beta=.54, p<.001)$. Being Christian was not significantly related to opposition in this analysis $(p=.719)$.

5. When repeating this analysis including being Christian as a covariate this yielded similar results for the indirect effect of TC (lower CI $=-.2988$, upper CI $=-.0466$ ) and of CC (lower CI $=.0622$, upper $\mathrm{CI}=.3054$ ).

6. For more information on TNS NIPO Consult, which is a consultancy company that conducts surveys and other studies among the Dutch population, see http://www.tns-nipo.com/

7. We chose to divide participants into four age cohorts (with approximately 15 years in between) in order to ensure that we had a sufficient amount of participants within each age cohort to assess the differences between the experimental conditions.

8. We performed these analyses using different age cohorts as the reference category. These analyses 
showed that there were no differences in the effect of the Christian manipulation between the three older age cohorts at $p$ (two-tailed $)<.05$.

9. To facilitate further interpretations, we conducted our main analyses using a single dummy variable contrasting the youngest to the older age cohorts.

10. We repeated the analyses including education and Christian religiosity as covariates, and this yielded similar results for the indirect effect of the tolerant manipulation (lower CI $=-.3627$, upper $\mathrm{CI}=$ $-.0249)$, as well as for the indirect effect of the Christian manipulation by age cohort interaction (lower CI $=.0492$, upper CI $=.9047$ ).

\section{References}

Aiken, L. S., \& West, S. G. (1991). Multiple regression: Testing and interpreting interactions. London, UK: Sage.

Alba, R. (2005). Bright vs. blurred boundaries: Secondgeneration assimilation and exclusion in France, Germany and the United States. Ethnic and Racial Studies, 28, 20-49. doi:10.1080/0141987042000280003

Amos Development Corporation. (2007). AMOS (16.0) [Computer software]. Spring House, PA: Amos Development Corporation.

Bilewicz, M. (2007). History as an obstacle: Impact of temporal-based social categorizations on Polish-Jewish intergroup contact. Group Processes and Intergroup Relations, 10, 551-563. doi:10.1177/1368430207081540

Bluck, S., \& Alea, N. (2008). Remembering me: The self-continuity function of autobiographical memory in younger and older adults. In F. Sani (Ed.), Self continuity: Individual and collective perspectives (pp. 55-70). New York, NY: Psychology Press.

Brown, R. (2010). Prejudice: It's social psychology (2nd ed.). Oxford, UK: Wiley-Blackwell.

Caldwell, C. (2009). Reflections of the revolution in Europe: Immigration, Islam and the West. London, UK: Penguin books.

Chandler, M. J., \& Proulx, T. (2008). Personal persistence and persistent peoples: Continuities in the lives of individual and whole cultural communities. In F. Sani (Ed.), Self continuity: Individual and collective perspectives (pp. 213-226). New York, NY: Psychology Press.

Coenders, M., Lubbers, M., Scheepers, P., \& Verkuyten, M. (2008). More than two decades of changing ethnic attitudes in the Netherlands. Journal of Social Issues, 64, 269-285. doi:10.1111/j.1540-4560.2008.00561.x

Condor, S. (1996). Social identity and time. In W. P. Robinson (Ed.), Social groups and identities: Developing the legacy of Henri Tajfel (pp. 285-315). Oxford, UK: Butterworth Heinemann.

Condor, S. (1997). "Having history": A social psychological exploration of Anglo-British autostereotypes. In C. C. Barfoot (Ed.), Beyond Pug's tour: National and ethnic stereotyping in theory and literary practice (pp. 213-255). Amsterdam, the Netherlands: Rodopi.

Dekker. G. (2007). Het Christelijk godsdienstig en kerkelijk leven [Christian religious and ecclesiastical life]. In T. Bernts, G. Dekker, \& J. de Hart (Eds.), God in Nederland 1996-2006 [God in the Netherlands 1996-2006] (pp. 12-76). Kampen, the Netherlands: Ten Have.

Epstude, K., \& Peetz, J. (2012). Mental time travel: A conceptual overview of social psychological perspectives on a fundamental human capacity. European Journal of Social Psychology, 42, 269-275. doi:10.1002/ejsp.1867

Fischer, R. (2011). Cross-cultural training effects on cultural essentialism beliefs and cultural intelligence. International Journal of Intercultural Relations, 35, 767-775. doi:10.1016/j.ijintrel.2011.08.005

Foner, N., \& Alba, R. (2008). Immigrant religion in the U.S. and Western Europe: Bridge or barrier to inclusion? International Migration Review, 42, 360-392. doi:10.1111/j.1747-7379.2008.00128.x

Gil-White, F. (1999). How thick is blood? The plot thickens...If ethnic ancestors are primordialists, what remains of the circumstantialist/primordialist controversy? Ethnic and Racial Studies, 22, 789-820. doi:10.1080/014198799329260

Haslam, N. (1998). Natural kinds, human kinds and essentialism. Social Research, 65, 291-314.

Haslam, N., Bastian, B., Bain, P., \& Kashima, Y. (2006). Psychological essentialism, implicit theories, and intergroup relations. Group Processes and Intergroup Relations, 9, 63-76. doi:10.1177/1368430206059861

Helbig, M. (Ed.). (2012). Islamophobia in the west: Measuring and explaining individual attitudes. London, UK: Routledge.

Hobsbawm, E., \& Ranger, T. (1983). The invention of tradition. Cambridge, UK: Cambridge University Press.

Hunsberger, B., \& Jackson, L. M. (2005). Religion, meaning and prejudice. Journal of Social Issues, 61, 807-826. doi:10.1111/j.1540-4560.2005.00433.x

Huntington, S. P. (2004). Who are we: The challenges to America's national identity. New York, NY: Simon \& Schuster.

Hutchinson, J., \& Smith, A. D. (1996). Ethnicity. Oxford, UK: Oxford University Press. 
Inglehart, R. (1990). Culture shift in advanced industrial society. Princeton, NJ: Princeton University Press.

Jetten, J., \& Hutchison, P. (2011). When groups have a lot to lose: Historical continuity enhances resistance to a merger. European Journal of Social Psychology, 41, 335-343. doi:10.1002/ejsp.779

Jetten, J., \& Wohl, M. J. A. (2012). The past as a determinant of the present: Historical continuity, collective angst, and opposition to immigration. European Journal of Social Psychology, 42, 442-450. doi:10.1002/ ejsp.865

Leyens, J.-P., Cortes, B. P., Demoulin, S., Dovidio, J. F., Fiske, S. T., Gaunt, R., ... Vaes, J. (2003). Emotional prejudice, essentialism and nationalism: The 2002 Tajfel lecture. European Journal of Social Psychology, 33, 704-717. doi:10.1002/ejsp. 170

Liu, J. H., \& Hilton, D. J. (2005). How the past weighs on the present: Social representations of history and their role in identity politics. British Journal of Social Psychology, 44, 537-556. doi:10.1348/014466605X27162

Liu, J. H., \& László, J. (2007). A narrative theory of history and identity: Social identity, social representations, society and the individual. In G. Moloney \& I. Walker (Eds.) Social representations and identity: Content, process and power (pp. 85-107). London, UK: Palgrave MacMillan.

Lowenthal, D. (1985). The past is a foreign country. Cambridge, UK: Cambridge University Press.

Mannheim, K. (1964). Das problem der generationen [The problem of generations]. In K. Mannheim (Ed.), Wissensoziologie [Sociology of knowledge] (pp. 509565). Berlin, Germany: Herman Luchterhand Verlag.

Pehrson, S., Vignoles, V. L., \& Brown, R. (2009). National identification and anti-immigrant prejudice: Individual and contextual effects of national definitions. Social Psychology Quarterly, 72, 24-38. doi:10.1177/019027250907200104

Preacher, K. J., \& Hayes, A. F. (2008). Asymptotic and resampling strategies for assessing and comparing indirect effects in multiple mediator models. Behavior Research Methods, 40, 879-891. doi:10.3758/ BRM.40.3.879

Reicher, S. (2008). Making a past fit for the future: The political and ontological dimensions of historical continuity. In F. Sani (Ed.), Self continuity: Individual and collective perspectives (pp. 145-158). Hove, UK: Psychology Press.

Riek, B. M., Mania, E. W., \& Gaertner, S. L. (2006). Intergroup threat and outgroup attitudes: A meta-analytic review. Personality and Social Psychology Review, 10, 336-353. doi:10.1207/ s15327957pspr1004_4
Sahdra, B., \& Ross, M. (2007). Group identification and historical memory. Personality and Social Psychology Bulletin, 33, 384-395. doi:10.1177/0146167206296103

Sani, F. (2008). Self continuity: Individual and collective perspectives. New York, NY: Psychology Press.

Sani, F., Bowe, M., \& Herrera, M. (2008a). Perceived collective continuity and social well-being: Exploring the connections. European Journal of Social Psychology, 38, 365-374. doi:10.1002/ejsp.461

Sani, F., Bowe, M., \& Herrera, M. (2008b). Perceived collective continuity: Seeing groups as temporally enduring entities. In F. Sani (Ed.), Self continuity: Individual and collective perspectives (pp. 159-172). Hove, UK: Psychology Press.

Sani, F., Bowe, M., Herrera, M., Manna, C., Cossa, T., Miao, X., \& Zhou, Y. (2007). Perceived collective continuity: Seeing groups as entities that move through time. European Journal of Social Psychology, 37, 1118-1134. doi:10.1002/ejsp.430

Sani, F., Herrera, M., \& Bowe, M. (2009). Perceived collective continuity and ingroup identification as defence against death awareness. Journal of Experimental and Social Psychology, 45, 242-245. doi:10.1016/j. jesp.2008.07.019

Sears, D. O. (1993). Symbolic politics: A socio-psychological theory. In S. Iyengar \& W. McGuire (Eds.), Explorations in political psychology (pp. 113-149). Durham, NC: Duke University Press.

Sibley, C. G., Liu, J. H., Duckitt, J., \& Khan, S. S. (2008). Social representations of history and the legitimation of social inequality: The form and function of historical negation. European Journal of Social Psychology, 38, 542-565. doi:10.1002/ejsp.449

Smeekes, A., Verkuyten, M., \& Poppe, E. (2011). Mobilising opposition towards Muslim immigrants: National identification and the representation of national history. British Journal of Social Psychology, 50, 265-280. doi:10.1348/014466610X516235

Smeekes, A., Verkuyten, M., \& Poppe, E. (2012). How a tolerant past affects the present: Historical tolerance and the acceptance of Muslim expressive rights. Personality and Social Psychology Bulletin, 38, 1410-1423. doi:10.1177/0146167212450920

Smith, A. D. (1998). Nationalism and modernism. London, UK: Routledge.

Sniderman, P. M., \& Hagendoorn, L. (2007). When ways of life collide: Multiculturalism and its discontents in the Netherlands. Princeton, NJ: Princeton University Press.

Triandafyllidou, A. (1998). National identity and the "Other." Ethnic and Racial Studies, 21, 593-612. doi:10.1080/014198798329784 
Turner, J. C., Hogg, M. A., Oakes, P. J., Reicher, S. D., \& Wetherell, M. S. (1987). Rediscovering the social group: A self-categorization theory. Oxford, UK: Blackwell.

Verkuyten, M. (2003). Discourses about ethnic group (de-)essentialism: Oppressive and progressive aspects. British Journal of Social Psychology, 42, 371-391. doi:10.1348/014466603322438215

Verkuyten, M. (2013). Justifying discrimination against Muslim immigrants: Out-group ideology and the five-step social identity model. British Journal of Social Psychology. Advance online publication (10 November 2011). doi:10.1111/j.2044-8309.2011.02081.x

Verkuyten, M., \& Yildiz, A. A. (2010). Religious consolidation and mobilization among Turkish Dutch Muslims. European Journal of Social Psychology, 40, 436-447. doi:10.1002/ejsp.635

Wagner, U., Christ, O., \& Heitmeyer, W. (2010). Antiimmigration bias. In J. F. Dovidio, M. Hewstone,
P. Glick, \& V. M. Esses (Eds.), The Sage handbook of prejudice, stereotyping and discrimination (pp. 361-376). London, UK: Sage.

Wohl, M. J. A., Branscombe, N. R., \& Reysen, S. (2010). Perceiving your group's future to be in jeopardy: Extinction threat induces collective angst and the desire to change the in-group. Personality and Social Psychology Bulletin, 36, 898-910. doi:10.1177/0146167210372505

Yzerbyt, V. Y., Castano, E., Leyens, J.-P., \& Paladino, M.P. (2000). The phenomenology of the ingroup: The interplay of identification, entitativity and overexclusion. In W. Stroebe \& M. Hewstone (Eds.), European review of social psychology (Vol. 11, pp. 257-295). Chichester, UK: Wiley.

Zolberg, A. R., \& Woon, L. L. (1999). Why Islam is like Spanish: Cultural incorporation in Europe and the United States. Politics and Society, 27, 5-38. doi:10.1177/0032329299027001002 